\title{
The Direct Anterior Approach to the Hip Joint
}

\author{
Iyer Krishna Mohan* \\ Consultant Orthopedic Surgeon, UK
}

*Corresponding author: Iyer Krishna Mohan, Consultant Orthopedic Surgeon, UK

Submission: 眥 January 17, 2018; Published: 監June 25, 2018

\begin{abstract}
Minimally invasive surgical techniques are an extremely important aspect of modern day hip replacements. The most significant progress all over the world in the evolution of total hip replacement is that the procedure can be done with much less invasive techniques which allow the patient to recover and therefore mobilize early. These techniques require minimum handling to prevent damage to periarticular soft tissues and preservation of bone substance to the maximum extent possible, which helps conserve bone mass and avoid damage to soft tissues, to thus allow faster restoration of hip function.
\end{abstract}

\section{Introduction}

I had devised an Approach to the Hip Joint Modified Posterior Approach to the Hip Joint 1981, along with the help and guidance of a Biomedical Engineer Dr. Martin Elloy, PhD attached, to the University of Liverpool, UK, at a time when there were considerable reports of dislocation of the hip joint using the conventional posterior Approach as described by Moore [1].

With long draw out interactions with Dr. John O Donnell of Australia, who is extremely comfortable saying that I continue to use DAA for my hip replacements, and I have been very happy with it that I cannot imagine changing to any other approach now. I developed an interest in the Direct Anterior Approach to the Hip Joint and have used in initially in Hemiarthroplasty in a few cases with a radical change in my thinking of this Approach, which is helpful to the patient tremendously, in that there is no need to osteotomise the greater trochanter and hence avoids any complications related to the union of the greater trochanter, such as non-union or fibrous union, but most importantly prevents dislocation of the Hip Joint which was the main purpose of me devising the Modified Posterior Approach to the Hip Joint, which I had been using till today. Due to these multiple simple advantages offered by this Approach, I would encourage to recommend this Direct Anterior Approach to the Hip Joint to the newer generation of Orthopedic Surgeons wherever feasible, though it has a steep learning curve in the initial stages.

The most effective surgical approach for the Hip Joint remains controversial, as the Hip joint is likened to a motorway roundabout with numerous different approaches and exits. There are more than 100 different approaches to the Hip Joint described in literature (Figure 1).

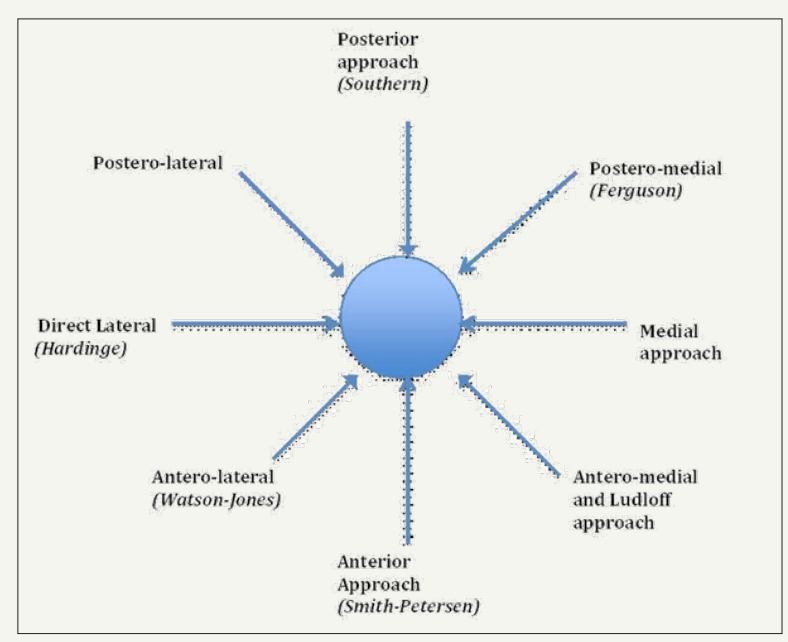

Figure 1: Figure reproduced with the kind permission of Amarasekera [2]. 


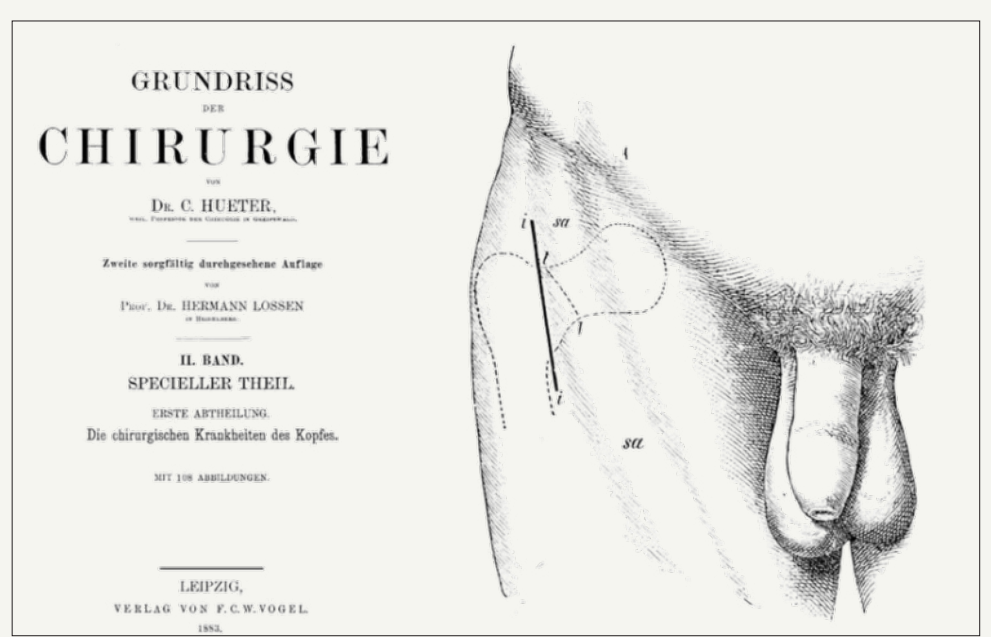

Figure 2: Hueter's original publication.

Direct anterior approach (DAA) has become popular in the United states of America for past one decade as "minimally invasive muscle sparing approach" The first description [2,3] of the direct anterior approach to the hip joint (Figure 2) which provides an excellent exposure to the acetabulum, in primary or a revision total hip arthroplasty, which In contrast with conventional techniques, and hence direct anterior approaches (DAA) has gained popularity among the orthopedic hip surgeons the world over and patients for earlier recovery and mobilization.
This has progressed to such a point that some patients are able to have their surgery done as an outpatient procedure without any hospital admission, as mentioned in my book "Hip Joint in Adults: Advances and Developments" in chapter 18 as "Total hip in a day, setup and early experiences in outpatient hip surgery" [4], by Krieger \& Elias [5] Wiesbaden, Frankfurt, Germany. This is a chapter written wherein the Total Hip can be done as an outpatient procedure without any in-patient admission (Figure 3) on selected patients as a day case, without any fear of dislocation.

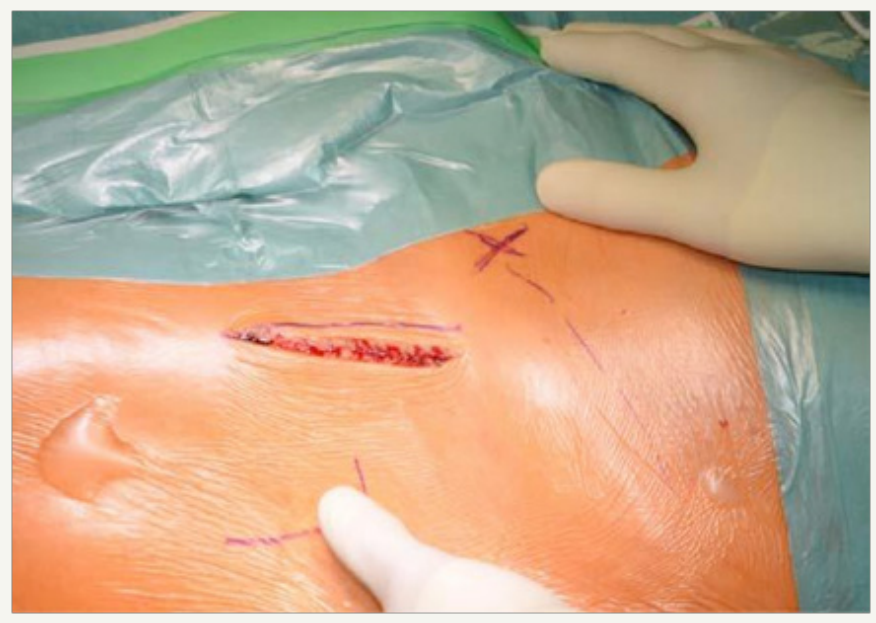

Figure 3: Intra-op single incision anterior approach [5].

Outpatient total hip replacement (THR) procedures are increasing in the orthopedic surgery community, especially in the USA, Scandinavia, and the Benelux countries. This was presented at the 10th Int. Conference of Arthroplasty in Madrid, Spain on December 04-05, 2017.

Krieger \& Elias [5] were the first authors to report setup and first clinical experiences of ambulatory and very fast track THR in Germany. From June 2016 until August 2017 they have treated 41 patients (22 female/19 male, average age 60 years) who underwent primary total hip replacement surgery at the orthopedic surgery day clinic of the GPR Hospital Rüsselsheim, Germany with a direct anterior approach and all under general anesthesia. All patients were carefully selected and enrolled in the so called Hip-in-a-Day program [6].

The Direct Anterior Approach can be helpful in

1. Outpatient procedure as in certain advanced centres in Frankfurt, Germany.

2. The Direct Anterior Approach in Hemiarthroplasty. 
3. Direct Anterior Approach in Primary Total Hip Arthroplasty.

4. Direct Anterior Approach in Revision Hip Arthroplasty.

This approach provides a direct visualization of the acetabulum and the anterior iliac spine landmarks to allow reference for appropriate cup positioning as it utilizes anterior internervous and intermuscular plane.
I have tried to get accustomed to this DAA by initially as I was accustomed to the Modified Posterior Approach to the Hip Joint and by doing a few cases of Hemiarthroplasty by the DAA as shown in Figure 3-5, and am fully convinced of the usefulness of this Approach to the Hip Joint for the younger generation of Orthopedic Surgeons in the world, because of multiple advantages. O’Donnell [7] Associate Professor, Hip Arthroscopy Australia is also the Convener and Host, Melbourne ISHA ASM 2018, and would encourage all Orthopedic Surgeons worldwide to attend the same.

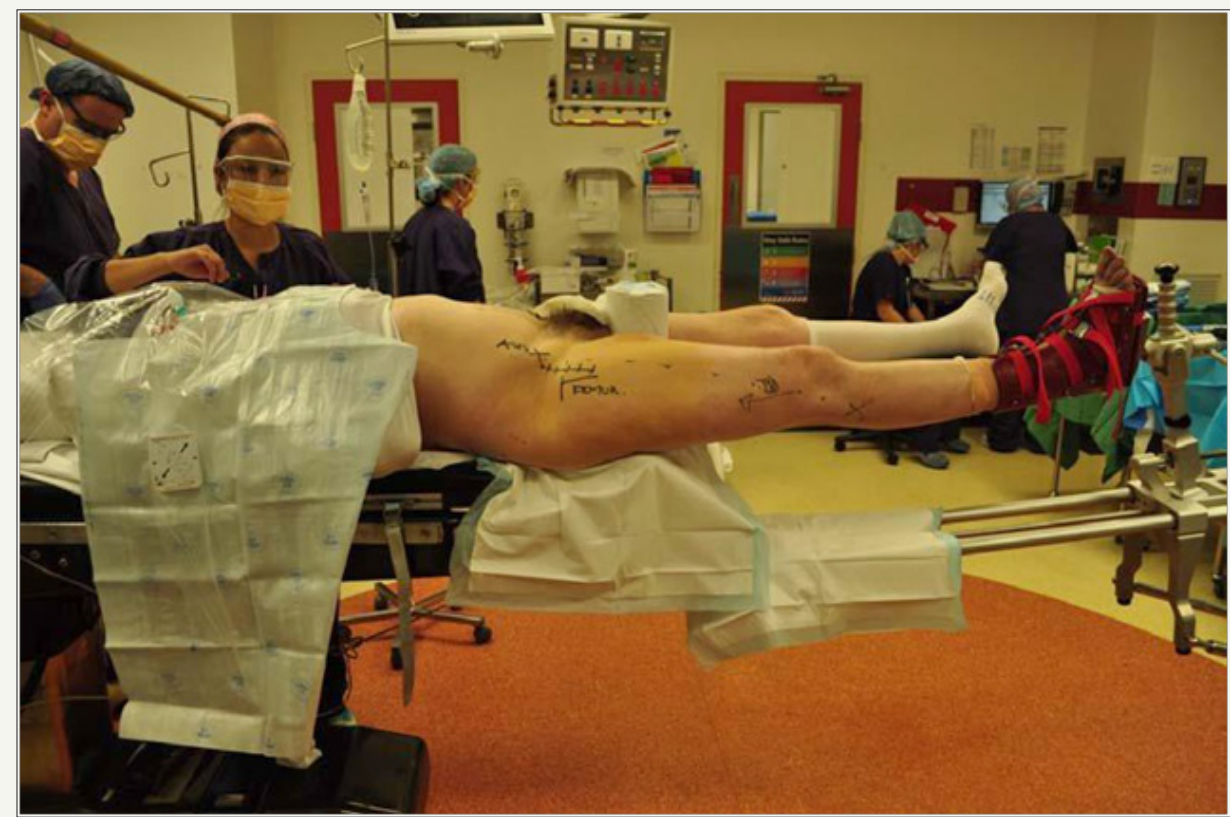

Figure 4: Patient positioned for right total hip replacement [7].

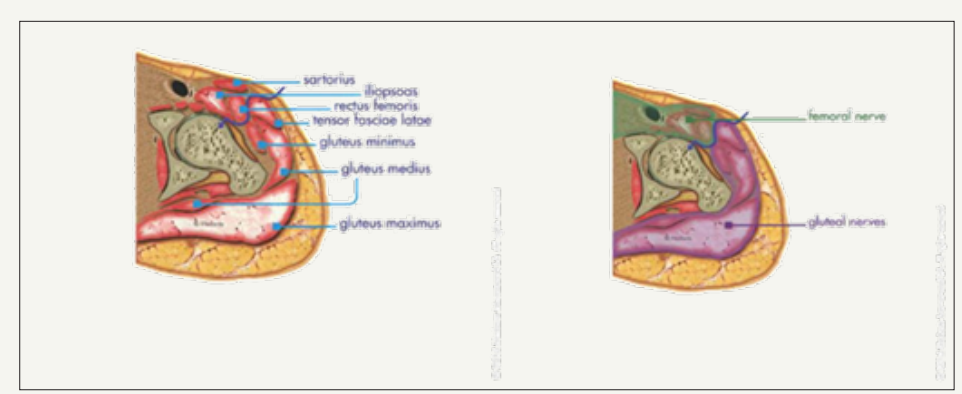

Figure 5: The approach is both intermuscular and interneural [8].

\section{References}

1. Moore AT (1957) The self locking metal Hip Prosthesis. J BoneJt Surg 39A: 811.

2. Amarasekera $H$ (2012) Figure reproduced with the kind permission of Amarasekera H, Orthopedic Research Fellow/PhD Student, Warwick Medical School, University of Warwick, UK.

3. UK from the book Arthroplasty-Update, ISBN 978-953-51-0995.

4. Hueter C (1883) Funfte abtheilung: die verletzung und krankheiten des huftgelenkes neunundzwnzigtes capitel. Grundriss der chirurgie, $\left(2^{\text {nd }}\right.$ edn), FCW Vogel library, Leipzig, USA, pp. 129-200.
5. Krieger M, Elias MI (2018) Total hip in a day, setup and early experiences in outpatient hip surgery. Hip Joint in Adults: Advances and Developments, Pan Stanford Publishing, Singapore.

6. Direct anterior approach to the hip joint. Lambert Academic Publishing, Germany.

7. O'Donnell J (2018) Direct anterior approach to the hip joint. Hip Joint in Adults: Advances and Developments, Pan Stanford Publishing, Singapore. 
Creative Commons Attribution 4.0 International License

For possible submissions Click Here

Submit Article

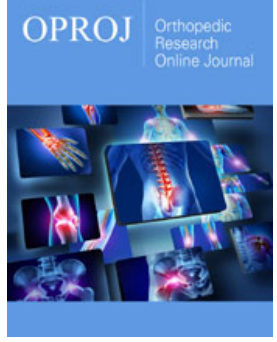

Orthopedic Research Online Journal

\section{Benefits of Publishing with us}

- High-level peer review and editorial services

- Freely accessible online immediately upon publication

- Authors retain the copyright to their work

- Licensing it under a Creative Commons license

- Visibility through different online platforms 